\title{
Association between Clinical Scores and Absence from Work after Knee Arthroscopy
}

\author{
Marius Ioniţescu ${ }^{1}$, Radu Prejbeanu ${ }^{1}$, Dinu Vermesan ${ }^{1}$, Jenel Marian Patrascu, Jr. ${ }^{1}$, \\ Roxana Onofrei ${ }^{2}$ and Horia Haragus ${ }^{1, *}$ \\ ${ }^{\text {I }}$ Department of Orthopedics and Trauma, Victor Babes University of Medicine and Pharmacy, 2 Eftimie Murgu \\ Square,30004I Timisoara, Romania; mariusionitescu@gmail.com (M.I.); raduprejbeanu@gmail.com (R.P.); \\ dinu@vermesan.ro(D.V.); patrascujenel@yahoo.com (J.M.P.J.) \\ ${ }^{2}$ Department of Rehabilitation, Physical Medicine and Rheumatology, Victor Babes University of Medicine and \\ Pharmacy, 2 Eftimie Murgu Square, 30004I Timisoara, Romania; onofrei.roxana@umft.ro \\ *Correspondence: horia.haragus@umft.ro
}

Submitted: 14 September 2020; Accepted: 12 October 2020; Published: 20 October 2020

\begin{abstract}
I) Background: To determine the association between patient-reported outcome measures and return to work after knee arthroscopy. (2) Material and Methods: Retrospective analysis of data on patients scheduled for knee arthroscopy in 2019 for which symptom severity was available using International Knee Documentation Committee subjective knee evaluation form (IKDC), Knee Disability And Osteoarthritis Outcome Score For Joint Replacement (KOOS JR), Tegner Lysholm scale and Euroqol EQ $5 D_{5} L$. Paid sick leave was retrieved from electronic patient records. (3) Results: 6r patients (mean age $46.44 \pm 7.6 \mathrm{r}$ years, $28(45.9 \%)$ males) met the inclusion criteria. All patients ultimately returned to work. Forty-six $(75.41 \%)$ received a mean of 28.5 (range 7-68) days of paid medical leave after surgery. Of those, three patients were already on medical leave. There were no differences in demographics and clinical scores between patients who received paid sick leave and those who did not. No significant correlation was found between days of absence and clinical scores. (4) Conclusions: There was no association between absence from work and commonly used clinical scores in patients undergoing knee arthroscopy.
\end{abstract}

Keywords: knee joint surgery; arthroscopy; middle aged; outcome assessment; health care; return to work; sick leave

How to cite: Ioniţescu, M.; Prejbeanu, R.; Vermesan, D.; Patrascu, J.M., Jr.; Onofrei, R.; Haragus, H. Association between Clinical Scores and Absence from Work after Knee Arthroscopy. Timisoara Med. 2020, 2020(I), 2; doi:I0.35995/tmj20200IO2.

\section{Introduction}

Knee arthroscopy is one of the most common orthopedic surgeries performed worldwide [ $\mathrm{I}, 2]$. The joint is explored using a narrow camera through a small access, while another 'working' portal is used for specialized tools [3]. The most frequent indication is meniscal tear, followed by anterior cruciate ligament reconstruction and cartilage pathology in the middle-aged population $[1,2]$. 
During the postoperative convalescence, employees receive a variable amount of paid sick leave. This may represent an objective measure to quantify readiness of returning to work. It has been studied for many musculoskeletal conditions [4-9]; nonetheless, there are limited data for arthroscopic knee meniscectomy [Io,II].

Patient-reported outcome measures are simple questionnaires that provide an inside into ones health status, disease progression or treatment benefit $\left[\mathrm{I}_{2}, \mathrm{I}_{3}\right]$. They are the standard evaluation of symptom severity in musculoskeletal medicine.

Given the high prevalence of knee pain treated arthroscopically in the active, employed population we aimed to determine the possible association between patient-reported outcomes and time to return to work after knee arthroscopy.

\section{Materials and Methods}

We included patients with knee pain who underwent arthroscopy in our clinic during 2019, were employed at the moment of surgery and for which patient-reported outcomes were available from a previous study [14]. Diagnosis was supported by clinical examination and imaging studies (MRI-magnetic resonance imaging, where available) and confirmed arthroscopically according to current clinical practice guidelines $[2,3]$. We only included patients with non-reparable meniscal tears and/or non-reconstructed cartilage lesions. Anterior cruciate ligament reconstructions, meniscal sutures, chondroplasty or any other procedure were excluded.

Patients were evaluated using the international knee documentation committee subjective knee evaluation form (IKDC), the knee disability and osteoarthritis outcome score for joint replacement (KOOSJR), Tegner Lysholm scale and Euroqol EQ5 55 Index (converted using the UK tariff) and visual analogue scale (VAS) [13-16]. These questionnaires are among the most commonly used to evaluate knee function for the active population (IKDC and Tegner Lysholm), subjects with osteoarthritis (KOOSJR) and overall quality of life (EQs $\left.\mathrm{D}_{5} \mathrm{~L}\right)$.

Duration of paid sick leave was retrieved from the electronic data base. Neutrophil to lymphocyte ratio (NLR) was determined as the ratio between the absolute number of neutrophils and lymphocytes obtained from routine hematology panels retrieved from the hospital's electronic records. This is a readily available measure of general inflammation, used as a potential predictor of outcome in oncology and cardiovascular disease $[17]$. Tests were determined using Nihon Kohden Celltac 6500, Sysmex XT-40ooi or ADVIA $2 \mathrm{I} 2 \mathrm{O}$ analyzers.

An unpaired $t$-test was used to determine the difference between two means. Association was determined using a multiple linear regression model with dependent variable duration of paid sick leave using Prism 8 version 8.4.3 statistical software (GraphPad, San Diego, CA, USA). Predictor variables were Tegner Lysholm scale, IKDC, KOOSJR and EQ5D Index and VAS. The study protocol was approved by the Local ethics committee for scientific research ( $\mathrm{Nr}_{17}$ 6/2019) and was conducted in accordance with the Declaration of Helsinki. Specific informed consent was not required due to the retrospective nature of the study.

\section{Results}

From a total of IO4 available patient-reported outcome datasets, 6r patients (mean age $46.44 \pm 7.6 \mathrm{r}$ years, $28(45.9 \%)$ males) met the inclusion criteria. Forty retired, two unemployed and one with additional 
arthroscopic procedures were excluded. Thirty five patients had a tear of either the medial or the lateral meniscus and 24 of both. Eleven patients had normal cartilage, 28 grade I or 2 and 18 grade 3 or 4 cartilage lesions in at least one compartment, according to the modified Outerbridge classification [3,14]. Means and $\mathrm{SD}$ (standard deviations) for the parameters of the entire group are presented in Table I.

Table 1. Parameters of the study group.

\begin{tabular}{ccccccc}
\hline $\begin{array}{c}\text { Medical Leave } \\
(n=61)\end{array}$ & $\begin{array}{c}\text { Tegner } \\
(n=60)\end{array}$ & $\begin{array}{c}\text { IKDC } \\
(n=59)\end{array}$ & $\begin{array}{c}\text { KOOSJR } \\
(n=57)\end{array}$ & $\begin{array}{c}\text { EQ5D Index } \\
(n=59)\end{array}$ & $\begin{array}{c}\text { EQ5D VAS } \\
(n=57)\end{array}$ & $\begin{array}{c}\text { NLR } \\
(n=44)\end{array}$ \\
\hline $21.52 \pm 16.15$ & $52.58 \pm 17.6$ & $34.84 \pm 14.49$ & $14.32 \pm 4.5 \mathrm{I}$ & $0.55 \pm 0.24$ & $68.16 \pm 18.19$ & $2.11 \pm 0.85$ \\
\hline
\end{tabular}

Tegner Lysholm knee rating scale: range o-Ioo, with roo representing no impairment [16]; IKDC (International Knee Documentation Committee-subjective knee form): range o-Ioo, with Ioo representing no impairment [I4]; KOOSJR (Knee disability and Osteoarthritis Outcome Score for Joint Replacement): raw score range o-28, with 28 representing total knee disability [14]; EuroQol EQ5D5L Index: using the UK tariff range -0.285 to I, with negative values for health states worse than death, o death and I best health state possible and VAS (Visual analog scale): range o-Ioo, with roo representing best health state imaginable [15]; Neutrophil to lymphocyte ratio (NLR): normal mean value I.65 [ \pm I.96 SD: $0.78-3.53]$ (95\% CI [0.75-0.8I] and [3.40-3.66]) [17]; presented as means and SD.

All patients ultimately returned to work. Forty-six (75.41\%) received a mean of 28.5 (SD I2, range 7-68, $95 \% \mathrm{CI} 25-32$ ) days of paid medical leave after surgery. Of those, three patients were already on absence from work due to sickness. For the rest (I5), there were no data regarding why they did not require paid medical leave. There were no differences in demographics and clinical scores between patients who received paid sick leave and those who did not. There were no relevant surgical complications. Comparative descriptive data are shown in Table 2.

Table 2. Comparison between those with and without paid medical leave.

\begin{tabular}{lll}
\hline & Yes $(\boldsymbol{n}=\mathbf{4 6})$ & No $(\boldsymbol{n}=\mathbf{1 5})$ \\
\hline Age & $46.15 \pm 7.73$ & $47.33 \pm 7.42$ \\
Males $(n, \%)$ & $2 \mathrm{I}(45.6)$ & $7(46.6)$ \\
Tegner score & $52.2 \pm \mathrm{I} 8.06$ & $53.73 \pm \mathrm{I} 6.67$ \\
IKDC & $34.55 \pm \mathrm{I} 4.9$ & $35.79 \pm 13.54$ \\
KOOSJR & $\mathrm{I} 4.05 \pm 4.72$ & $\mathrm{15.14} \pm 3.84$ \\
Index & $0.56 \pm 0.24$ & $0.53 \pm 0.24$ \\
VAS & $68.37 \pm \mathrm{I} 8.95$ & $67.5 \pm \mathrm{I} 6.26$ \\
NLR & $2.15 \pm 0.83$ & $\mathrm{I} .96 \pm 0.97$ \\
\hline
\end{tabular}

Tegner Lysholm knee rating scale; IKDC (International Knee Documentation Committee-subjective knee form), KOOSJR (Knee disability and Osteoarthritis Outcome Score for Joint Replacement), EuroQol EQ5D5L Index and VAS (Visual analog scale) and Neutrophil to lymphocyte ratio (NLR); presented as means and SD.

No significant correlation was found between the number of days of paid medical leave and any of the clinical scores and parameters (Table 3 ). However, a significant inverse correlation was found between absence from work and one or two meniscal lesions $(r=-0.309, p=0.017)$.

Table 3. Correlation between days of paid medical leave and patient-reported outcomes.

\begin{tabular}{cccccc}
\hline & Tegner & IKDC & KOOSJR & EQ5D & EQ5D VAS \\
\hline \multirow{2}{*}{ Medical leave } & -0.14 & -0.216 & 0.088 & -0.104 & -0.15 \\
& $(p=0.28)$ & $(p=0.10)$ & $(p=0.52)$ & $(p=0.43)$ & $(p=0.26)$ \\
\hline
\end{tabular}

The Spearman correlation coefficients and corresponding $p$-values. 


\section{Discussion}

Clinical outcome scales are essential instruments for patient centered care and performance of health service providers $\left[\mathrm{IO}, \mathrm{I}_{3}\right]$. Yet, in our study there was no association between commonly used patient-reported outcomes and duration of absence from work after knee arthroscopy.

In our cohort, three quarters of patients received a paid medical leave for a mean of 4 weeks and only less than a third (29.5\%) returned to work before 2 weeks. That is significantly higher than reported by similar studies of Lubowitz et al.-return to work of $94 \%$ by 2 weeks and Bergkvist et al._one third of patients had an absence from work of more than 2 weeks [Io,II]. Apart from possible sociodemographic and cultural differences, this may be due in part to our retrospective nature and lack of proper identification of self-employed who may have not applied for paid medical leave, since factors other than surgery may explain prolonged sick leave [II]. We used the readily available NLR as a measure of general inflammatory response, but this showed no association. Even in rheumatic patients, it seems that subjective measures of pain and disability were more likely to influence subsequent sick leave than markers of inflammation and treatment response such as erythrocyte sedimentation rate, and C-reactive protein [I8].

Incipient osteoarthritis is a significant burden for the middle aged working population. It is a disease of the entire joint, affecting cartilage, subchondral bone, menisci and synovium, common in patients undergoing arthroscopic meniscectomy [19]. Treatment options are limited and evidence supporting their efficacy varies. Conservative measures are first recommended and include weight loss, activity modifications, physical therapy, non-steroidal anti-inflammatory medication and intraarticular instillations. Surgical options are arthroscopy (lavage, partial meniscectomy, chondroplasty and loose body removal), filling of focal cartilage lesions, lower limb mechanical axis realignment (high tibial osteotomy to correct varus deviation). Arthroplasty is reserved for advanced disease, ideally in elderly (over 65 years) [2,13,20,2I].

There has been an ongoing debate over the medium- and long-term benefit for arthroscopic meniscectomy for both degenerative and traumatic tears [I,2]. Several level I studies have shown comparable outcomes to structured physical therapy or sham surgery. Predictors for less improvement are generally considered osteoarthritic changes but determinants are vague. Arthroscopic meniscectomy is considered safe, minimally invasive and provides short- and mid-term symptom relief for most patients, which has maintained its popularity among surgeons $[\mathrm{I}, 2, \mathrm{IO}, \mathrm{II}]$. Most patients return to work after high tibial osteotomy by io to 22 weeks and after 94.5 days $\left( \pm_{77}\right)$ following combined single-stage autologous chondrocyte implantation and high tibial osteotomy $[8,9]$. In a systematic review, 71 to $83 \%$ of patients return to work after total knee arthroplasty, with sociodemographic, health and job characteristics as determinants [7].

Our study has several limitations. We did not account for type of work, self-employment, potential activity modifications when returned to work or litigations, factors that may influence paid medical leave [4-I2].

Compared to other musculoskeletal pathologies, knee arthroscopy is a safe procedure with a modest absence from work. Luyckx et al. found an absence from work after arthroscopic subacromial decompression of a mean of II weeks. Self-employed workers returned to work significantly sooner (median of I week) than manual laborers (I2 weeks) [4]. Aagaard et al. reported that $97 \%$ of arthroscopically reconstructed acute traumatic rotator cuff tears returned to full-duty work after a median time of 5.O (I.I-IO.5) months. Preoperative work level and dominant side were significant confounders [5]. Mean duration of sick leave ranged from 0.8 to 20 weeks for lumbar radiculopathy. A total of $3-100 \%$ of patients resumed work within o.I-240 months post-surgery. The most important predictors were preoperative work status, comorbidities, 
age, gender and duration of preoperative symptoms. The length of sick leave could be predicted from the preoperative level of pain, disability, depression and surgical technique [6].

\section{Conclusion}

In our study, there was no association between the amount of absence from work and commonly used clinical scores in patients undergoing knee arthroscopy.

Author Contributions: Conceptualization, M.I. and H.H.; methodology, J.M.P.J.; software, R.O.; validation, R.O., and H.H.; formal analysis, J.M.P.J.; investigation, M.I.; resources, M.I.; data curation, R.O.; writing-original draft preparation, H.H.; writing-review and editing, H.H.; visualization, R.P.; supervision, D.V.; project administration, R.P.; funding acquisition, D.V. All authors have read and agreed to the published version of the manuscript.

Funding: This research received no external funding.

Acknowledgments: We would like to offer our thanks to Andrei Ghiorghitoiu, MD.

Conflicts of Interest: The authors declare no conflict of interest.

\section{References}

I. Abram, S.G.F.; Judge, A.; Beard, D.J.; A Wilson, H.; Price, A.J. Temporal trends and regional variation in the rate of arthroscopic knee surgery in England: analysis of over I.7 million procedures between 1997 and 2017. Has practice changed in response to new evidence? Br. J. Sports Med. 2018, 53, 1533-1538. [CrossRef] [PubMed]

2. Beaufils, P.; Becker, R.; Kopf, S.; Matthieu, O.; Pujol, N. The knee meniscus: management of traumatic tears and degenerative lesions. EFORT Open Rev. 2017, 2, 195-203. [CrossRef] [PubMed]

3. Stetson, W.B.; Templin, K. Two- versus Three-Portal Technique for Routine Knee Arthroscopy. Am. J. Sports Med. 2002, 30, 108-III. [CrossRef] [PubMed]

4. Luyckx, L.; Luyckx, T.; Donceel, P.; Debeer, P. Return to work after arthroscopic subacromial decompression. Acta Orthop. Belg. 2011, 77, 737-742. [PubMed]

5. Aagaard, K.E.; Randeblad, P.; Abu-Zidan, F.M.; Lunsjö, K. Return to work after early repair of acute traumatic rotator cuff tears. Eur. J. Trauma Emerg. Surg. 2019, 46, 817-823. [CrossRef] [PubMed]

6. Huysmans, E.; Goudman, L.; Van Belleghem, G.; De Jaeger, M.; Moens, M.; Nijs, J.; Ickmans, K.; Buyl, R.; Vanroelen, C.; Putman, K. Return to work following surgery for lumbar radiculopathy: A systematic review. Spine J. 2018, 18, 1694-1714. [CrossRef] [PubMed]

7. Tilbury, C.; Leichtenberg, C.; Tordoir, R.; Holtslag, M.; Verdegaal, S.; Nelissen, R.; Vlieland, T.V. THUo437 Return to Work after Total Hip and Knee Arthroplasty: Results from A Prospective Cohort Study. Ann. Rheum. Dis. 2014, 73, 333-334. [CrossRef]

8. Hoorntje, A.; Witjes, S.; Kuijer, P.P.F.M.; Koenraadt, K.L.M.; Van Geenen, R.C.I.; Daams, J.G.; Getgood, A.; Kerkhoffs, G.M.M.J. High Rates of Return to Sports Activities and Work After Osteotomies Around the Knee: A Systematic Review and Meta-Analysis. Sports Med. 2017, 47, 2219-2244. [CrossRef] [PubMed]

9. Bode, G.; Ogon, P.; Pestka, J.; Zwingmann, J.; Feucht, M.; Südkamp, N.; Niemeyer, P. Clinical outcome and return to work following single-stage combined autologous chondrocyte implantation and high tibial osteotomy. Int. Orthop. 2014, 39, 689-696. [CrossRef] [PubMed]

Io. Thorlund, J.B.; Englund, M.; Christensen, R.; Nissen, N.; Pihl, K.; Jørgensen, U.; Schjerning, J.; Lohmander, L.S. Patient reported outcomes in patients undergoing arthroscopic partial meniscectomy for traumatic or degenerative meniscal tears: comparative prospective cohort study. BMJ 2017, 356, j356. [CrossRef] [PubMed]

II. Morrissey, M.C.; Milligan, P.; Goodwin, P.C. Evaluating Treatment Effectiveness: Benchmarks for Rehabilitation After Partial Meniscectomy Knee Arthroscopy. Am. J. Phys. Med. Rehabilitation 2006, 85, 490-50I. [CrossRef] [PubMed]

I2. Lubowitz, J.H.; Ayala, M.; Appleby, D. Return to Activity After Knee Arthroscopy. Artbrosc. J. Arthrosc. Relat. Surg. 2008, 24, 58-61.e4. [CrossRef] [PubMed]

I3. Bergkvist, D.; Dahlberg, L.E.; Thorlund, J.; Neuman, P.; Zhou, C.; Englund, M. Sick leave before and after arthroscopic partial meniscectomy due to traumatic meniscal tear. Osteoarthr. Cartil. Open 2020, 2, 100040. [CrossRef]

I4. Todor, A.; Vermesan, D.; Haragus, H.; Patrascu, J.M.; Timar, B.; Cosma, D.I. Cross-cultural adaptation and validation of the Romanian International Knee Documentation Committee-subjective knee form. PeerJ 2020, 8, e8448. [CrossRef] [PubMed] 
I5. EuroQol Website. Available online: http://www.euroqol.org/about-eq-5d/how-to-use-eq-5d.html (accessed on 4 September 2019).

I6. Orthopaedicscores Website. Available online: https://www.orthopaedicscore.com/scorepages/tegner_ lysholm_knee.html (accessed on 4 September 2019).

I7. Forget, P.; Khalifa, C.; Defour, J.-P.; Latinne, D.; Van Pel, M.-C.; De Kock, M. What is the normal value of the neutrophil-to-lymphocyte ratio? BMC Res. Notes 2017, 10, 12. [CrossRef] [PubMed]

I8. Olofsson, T.; Söderling, J.K.; Gülfe, A.; Kristensen, L.; A Karlsson, J. Patient-Reported Outcomes Are More Important Than Objective Inflammatory Markers for Sick Leave in Biologics-Treated Patients With Rheumatoid Arthritis. Artbritis Rheum. 2018, 70, 1712-1716. [CrossRef] [PubMed]

19. Pihl, K.; Englund, M.; Lohmander, L.S.; Jørgensen, U.; Nissen, N.; Schjerning, J.; Thorlund, J.B. Signs of knee osteoarthritis common in 620 patients undergoing arthroscopic surgery for meniscal tear. Acta Orthop. 2016, 88, 90-95. [CrossRef] [PubMed]

20. A Van De Graaf, V.; Bloembergen, C.H.; Willigenburg, N.W.; A Noorduyn, J.C.; Saris, D.B.; A Harris, I.; Poolman, R.W. Can even experienced orthopaedic surgeons predict who will benefit from surgery when patients present with degenerative meniscal tears? A survey of 194 orthopaedic surgeons who made 3880 predictions. Br.J. Sports Med. 2019, 54, 354-359. [CrossRef] [PubMed]

2I. Grazina, R.; Andrade, R.; Bastos, R.; Costa, D.; Pereira, R.; Marinhas, J.; Maestro, A.; Espregueira-Mendes, J. Clinical Management in Early OA. Adv. Exp. Med. Biol. 2018, III-I35. [CrossRef]

(C) 2020 Copyright by the authors. Licensed as an open access article using a CC BY 4.0 license.

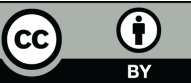

